\title{
Analysis of Grid connected Doubly Fed Induction Generator based Wind Turbine
}

\author{
G.Manohar $^{1}$, S.Venkateshwarlu ${ }^{2}$ \\ ${ }^{1}$ CVR College of Engineering/EEE Department, Hyderabad \\ manohar.gangikunta@gmail.com \\ ${ }^{2}$ CVR College of Engineering/EEE Department, Hyderabad \\ svip123@gmail.com
}

\begin{abstract}
The most reliable system in the present era to harness the wind power efficiently is grid connected Doubly Fed Induction Generator (DFIG).According to the new grid codes the wind turbines should remain connected to the grid under the conditions of low voltage dips. Semiconductor Magnetic Energy storage system (SMES) coupled to DFIG can improve the voltage stability. The fault analysis of DFIG connected to grid is simulated using the MATLAB simulink and tripping times are recorded for various faults.
\end{abstract}

Index Terms- Crow bar circuits, Doubly Fed Induction Generator (DFIG), Low Voltage Ride Through (LVRT),

Semiconductor Magnetic Energy Storage (SMES)

\section{INTRODUCTION}

With the tremendous increase in electrical energy and pollution problems, non conventional energy has become an important energy source. Wind energy has proved to be promising and economical non conventional energy and fast growing renewable energy. Due to its ability to control the pitch angle and produce high amount of power, doubly fed induction generator (DFIG) based wind farms became the first choice of the private wind power generating companies. The terminal voltage and frequency will vary with wind speed and load; whenever induction generator is supplying power to an isolated system, an excitation capacitor is required .Even under the windy conditions also both the voltage and frequency can be controlled smoothly using DFIG

Reduction of mechanical stress on the wind turbine, power quality improvement and increased energy capture are made possible with the DFIG based variable speed wind turbines. Rotor of the doubly fed induction generator is connected to grid through back to back converters, but stator windings of DFIG are directly connected to the electric grid The power electronic converters act as frequency converter and rating of these converters are generally 0.3 times the generated power [1-4].

\section{Power Flow In DFig}

The basic block diagram of Doubly Fed Induction Generator Connected to the grid is shown in Fig.1.Here back to back converters with DC link are connected in rotor circuit, the one which is connected to the rotor slip rings is called rotor side converter and the one which is connected to the electric grid is called source side converter or grid converter. The sources of these converters have very low inductance and hence they are voltage sourced converters and the switches that are used in this converter can be turned off by using either voltage or current commutation techniques .The voltage source converter is capable of generating AC voltage from a DC source.

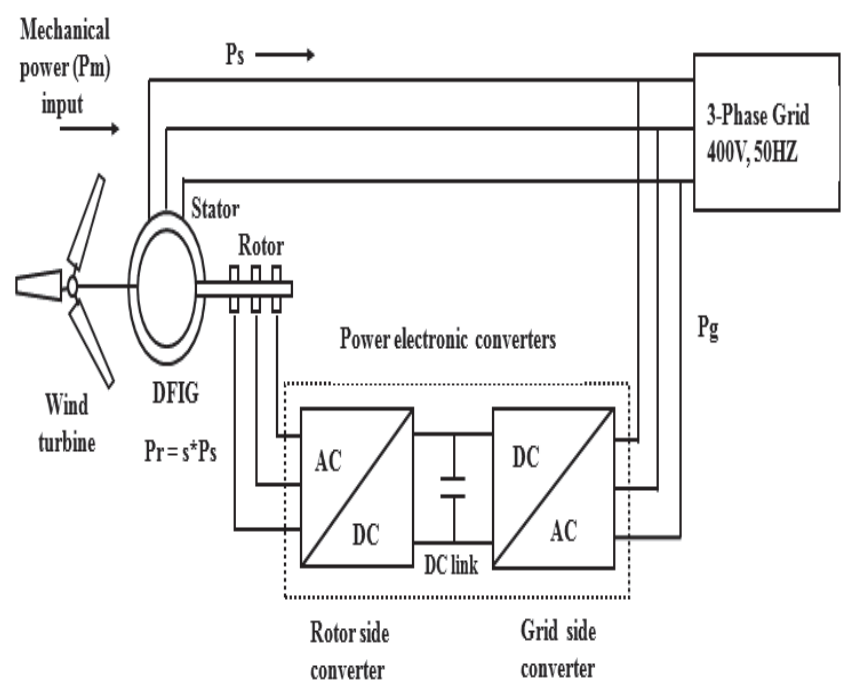

Fig.1.DFIG system with power electronic converters

The two modes of Doubly Fed Induction Generator are namely sub synchronous mode and super synchronous mode. If the speed of the rotor of the induction machine is less than synchronous speed, it operates like induction motor and DFIG is said to be operating in sub synchronous mode and if the rotor of the induction machine is more than synchronous speed, then induction machine is operating like induction generator and DFIG is acting in super synchronous mode. The power in the rotor of a doubly fed induction machine (i.e. of the slip ring type) has three components. These are i) the mechanical power $\mathrm{Pm}$ transferred from the rotor to the shaft of the machine; ii) the electromagnetic power or air gap power Ps transferred from the stator windings to the the rotor windings through the air gap iii) the slip power Pr which is conveyed between the rotor winding and any peripheral source or load (e.g. a converter) through the rotor slip-rings. The various components of rotor power during different modes of operation are shown in Fig.2. 


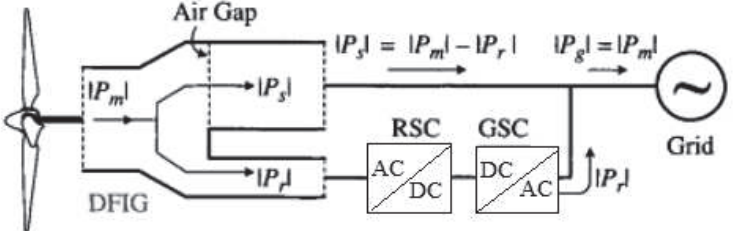

(a) Supersynchronous mode

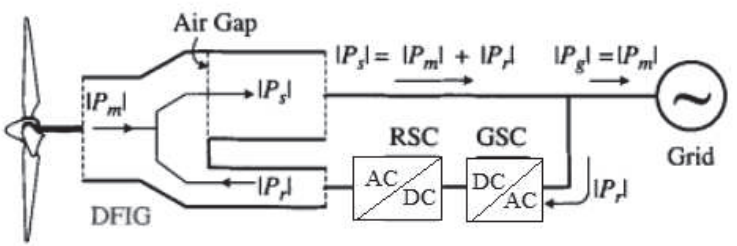

(b) Subsynchronous mode

Fig.2.Power flow in DFIG conversion system

Doubly fed induction generator connected to grid can be operated in two modes namely sub-synchronous mode and super synchronous mode .Rotor speed of DFIG is less than the speed of rotating magnetic field in sub synchronous mode. During this mode of operation motoring torque is produced. In order to use the motoring torque rotor circuit of DFIG needs negative power. This can be attained by regulating the voltage that is infused to the rotor circuit. Now the rotor circuit receives the power from the source though source side converter and DC link capacitor.

In super synchronous mode of operation rotor speed of DFIG is more than the speed of rotating magnetic field and slip is less than zero. In order to provide additional generating power to the grid from the charged DC link capacitor, the phase sequence of either rotor currents or rotor voltages must be inverted. Due to the variations in the velocity of wind, the magnitudes of currents in the rotor circuit and hence as a result, rotor voltages also change

\section{DFIG WITH SMES}

In spite of good performance of the DFIG, there are some problems which are to be addressed when large capacity wind farms with DFIGs are to be linked with the electrical grid. The foremost quandary is the power quality induced due to variations of power. The ability of doubly fed induction generator to control the variation in voltage is pretty low, particularly in windy and turbulent situations. The next quandary is the functioning of DFIG at the time of faults which are occurring in the electric grid. Faults that occurs in the interconnected power system, even very distant from the location of the wind farm, can create a voltage plunge at the common point of coupling of the wind turbine and grid. The plunge in the grid voltage will result in boosting in stator current of the DFIG, as a result over currents are induced in the rotor of DFIG and back to back converters. As the large capacity wind farms with DFIGs are penetrating in to power system network, the ride through competence is almost obligatory and stipulated for DFIG to diminish the undesirable and worst effect on the stability of the power system. One of the preferred solutions to crack the above mentioned problems is the energy storage unit which can handle the transfer of energy caused by variations in power or grid fault [5-9].

A chopper connected across the DC link of a doubly fed induction generator can control the amount of power generated as well as energy storage system, This energy storage system made up of super mantic material, possess highly efficient energy storage, fast response and power controllability The SMES unit is operated to trim down the power quality issues caused by power variations and enhance the under voltage ride through fault capability for the large scale DFIG based wind farms connected to the grid

The circuit diagram employing SMES unit for controlling DC link voltage for a doubly fed induction generator is shown in Fig.3.The excitation system is comprising of back to back converters with DC chopper and super conducting magnet generally made up of niobium titanium(NbTi) or niobium $\operatorname{tin}\left(\mathrm{Nb}_{3} \mathrm{Sn}\right)$. The excitation system in the energy storage unit must possess the properties of good dynamic power response and high energy storage efficiency. So, the superconducting magnet is selected as the energy storage unit of the excitation system, it is set at the DC side of the two converters. The DC chopper is efficiently operated in order to control the power transfer effectively between the super conducting magnet and the rotor of the DFIG or the power grid.

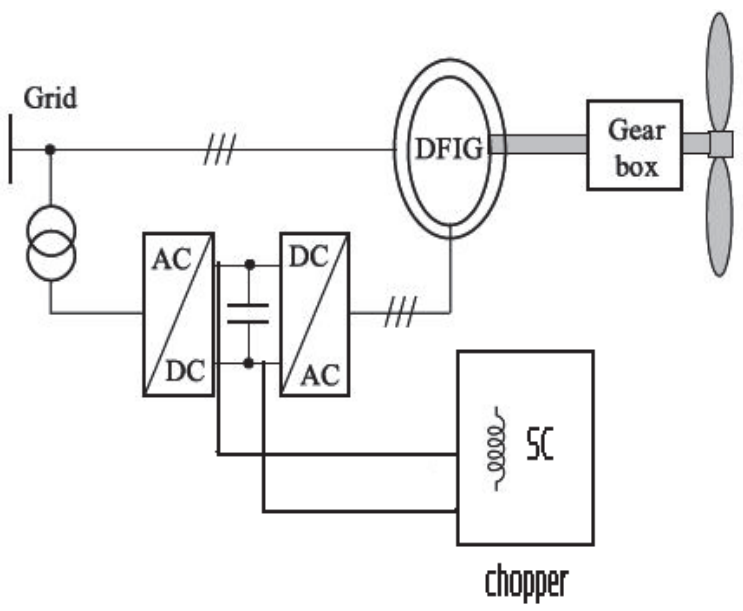

Fig.3.The circuit diagram of DFIG wind power system based on SMES

\section{Voltage Dips AND Under VOLTAGE RIDE THROUGH}

Involvement of research studies and wind farm developers have confirmed that faults occurring in the electric grid, badly affect the concert of the wind farms. The different types of faults that affect a wind farm are summarized in [10] and are broadly categorised as symmetrical and non-symmetrical faults. Real grid codes specify only about symmetrical faults, because they affect the stability of the electric grid very harmfully. But nonsymmetrical faults are further challenging to deal with doubly fed induction generators. 
According to new grid code requirements, the large capacity wind farms must stay connected to grid even under conditions of severe voltage dips. If the wind farm is suddenly disconnected, it further contributes to the voltage dip, with terrible consequences. Under the conditions of voltage dips, the stator voltage of DFIG suddenly decreases. Due to this the stator flux cannot track stator voltage. As a result, the stator flux becomes almost stationary. The rotor keeps on rotating and high slip is generated (as synchronous speed of the induction motor is very low).Since the rotor induced voltage is proportional to slip; high voltage is applied across the rotor side converters. Hence a security mechanism is needed to guard the power electronic converter connected to the rotor from the over voltages and over currents caused by the voltage dips.

The standard practice to crack the problem of voltage sags is to connect a crowbar circuit to the rotor of the wind generator. In case of voltage dips, crowbar circuit shorts the rotor of DFIG and the power electronic converter connected to the rotor is safely protected [11]. Even though there are many types of crow bar circuits available, diode bridge and anti-parallel thyristor types are most commonly used Usage of less number of thyristors and easy controllability made the diode bridge crowbar circuit more attractive than anti-parallel thyristor and other crow bar circuits. The crowbar circuit is triggered on, under two different situations. Firstly when DC link capacitor voltage reaches saturation, or when current in the rotor circuit exceeds the pre determined value. Crow bar is activated, since there is no control on the turning off of thyristors. According to the new grid codes , the wind farms should be connected to the grid during the voltage dip. Grid codes of the different countries of the world need not be similar. Some of the grid codes (Grid code of E.on, a major utility company in Germany) are very particular about the reactive power contribution of the wind farms under voltage dip conditions and hence to maintain power factor in the desirable range. The Rotor side crow bar circuit is shown in Fig.4.

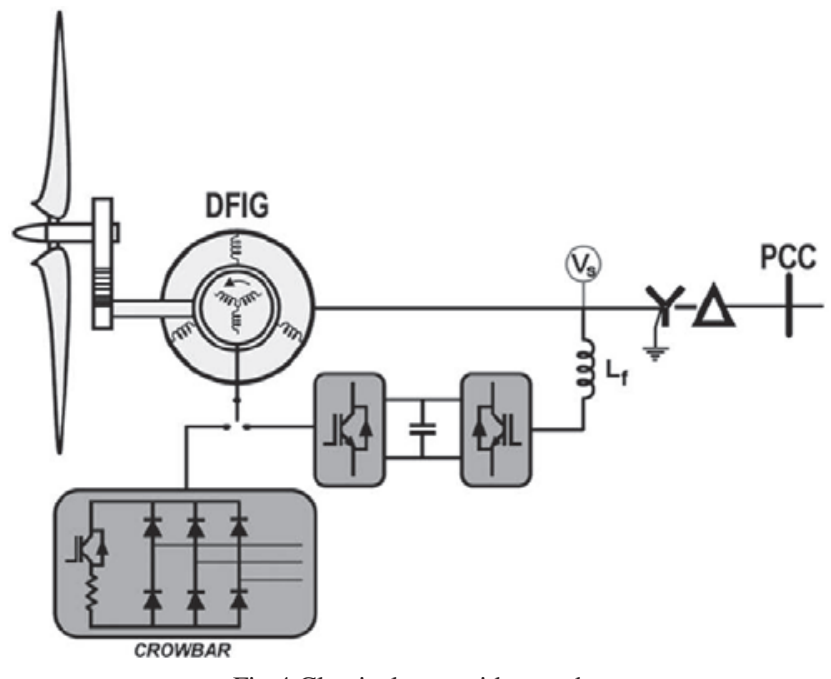

Fig.4 Classical rotor-side crowbar
There are several draw backs of rotor side crowbar. Major drawback is, DFIG loses its controllability once crowbar circuit is triggered. In the above mentioned situation DFIG absorbs huge amount of reactive power from the grid which makes further decrease in the grid voltage. In order to overcome the above drawback, Stator side crowbar circuit was proposed in [12-14] as shown in Fig. 5

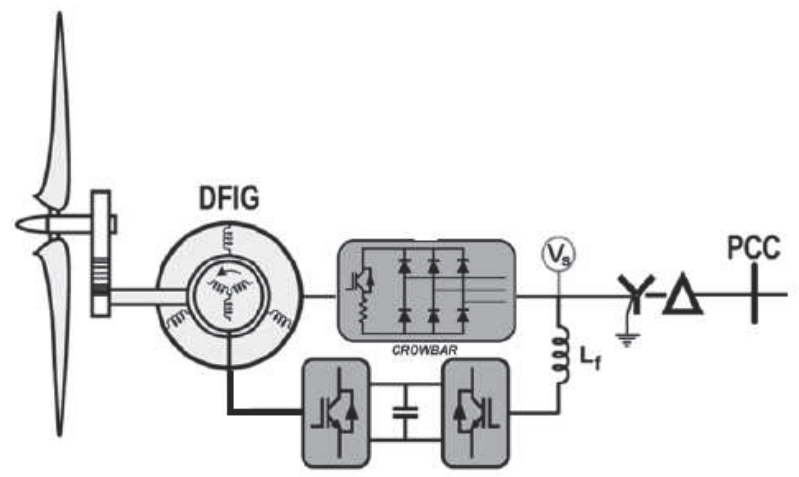

Fig.5. Stator side crowbar circuit

The limitation of stator side crowbar circuit is, its conduction losses are high because the bi-directional switches are in on condition during normal operation. Care should be taken while designing the power electronics so as to minimise the losses.

Another approach for low voltage ride through problem is using Energy Storage System ( ESS) .In this system an effective energy storage system placed in between rotor side converter and stator side converter across the dc link capacitor voltage is shown in the Fig.6. Energy storage system simply consists of two bidirectional switches connected in series and ESS connected across one of the switch. ESS based methods have ability to control the doubly fed induction generator during the fault too. Necessity of additional energy storage systems leads to the additional cost and increases system complexity [15-17].

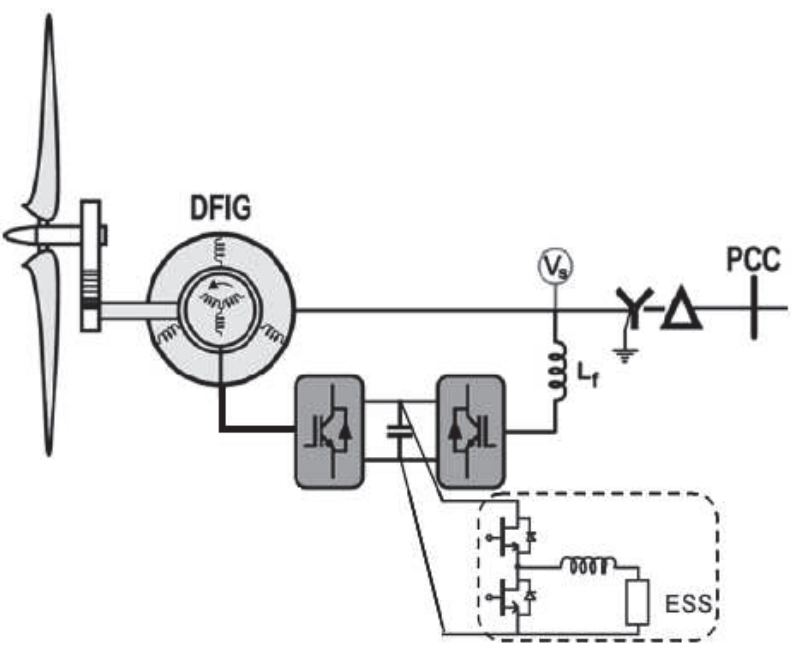

Fig.6 DFIG-Based wind turbine equipped with ESS

Connecting a parallel grid side rectifier (PGSR) with series grid side converter (SGSC) is an alternative 
approach to solve the under voltage ride through problems as shown in Fig.7. In this, circuit arrangement generator side converter recuperates the slip into DC link as in conventional doubly fed induction generator. The major function of series connected grid side converter is to inject the DC link power into the electric grid. Using this concept, the amount of power flow can be controlled over typical range above and below synchronous speed. But DFIG suffers at sub synchronous speeds [18].

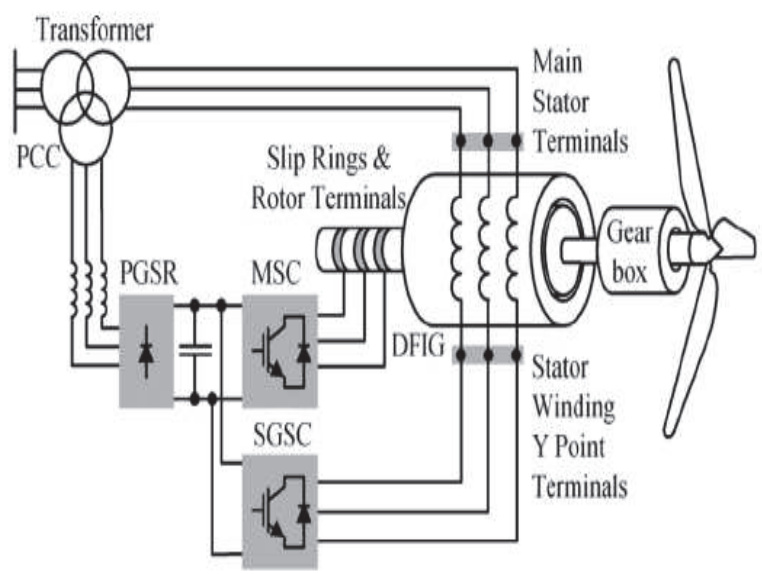

Fig.7 DFIG based wind turbine with PGSR and SGSC

\section{Simulation And ReSUlts}

A DFIG wind farm comprising of 6 units, each of 1.5 MW capacity (total of 9MW) is simulated .The wind farm exports power to the electric grid of $120 \mathrm{kV}$ by a $30 \mathrm{~km}$ transmission line which is maintained at $25 \mathrm{kV}$. A $2.3 \mathrm{kV}$, $2 \mathrm{KVA}$ plant consisting of inductive load and a $200 \mathrm{~kW}$ unity power factor load is connected to the same feeder at $25 \mathrm{kV}$ bus. MATLAB SIMULINK diagram of wind farm with capacity of $9 \mathrm{MW}$ joined to $120 \mathrm{kV}$ grid is shown in Fig.8

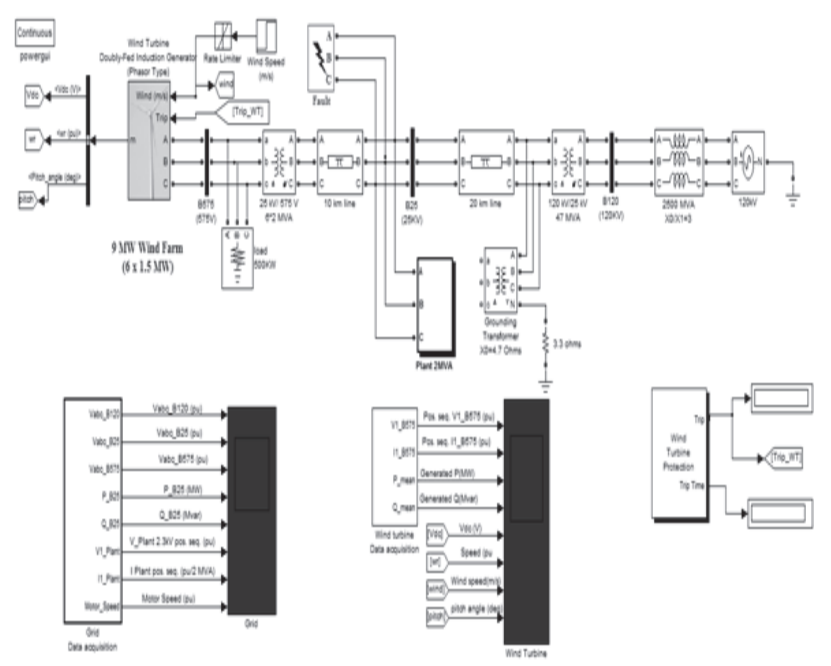

Fig. 8 Simulation diagram of a 9MW wind farm connected to $120 \mathrm{kV}$ grid

\section{A. Simulation of voltage sag on $120 \mathrm{kV}$ bus system}

Voltage sag resulting from a remote fault is simulated and its effect is observed. A $0.15 \mathrm{pu}$ voltage drop lasting $0.5 \mathrm{sec}$ is programmed to occur at $5000 \mathrm{~ms}$ Control mode of the wind farm is in VAR regulation with zero active power reference and velocity of wind is set at $8 \mathrm{~m} / \mathrm{s}$. We observe that wind farm produces $1.87 \mathrm{MW}$ and at $\mathrm{t}=5000 \mathrm{~ms}$ the voltage drops $0.9 \mathrm{pu}$ and at $5.22 \mathrm{sec}$. Now the plant trips because an under voltage is lasting for more than $200 \mathrm{~ms}$ has been detected. The plant current falls to zero. The wind farm active power $\mathrm{P}$ and plant current are shown in Fig.9

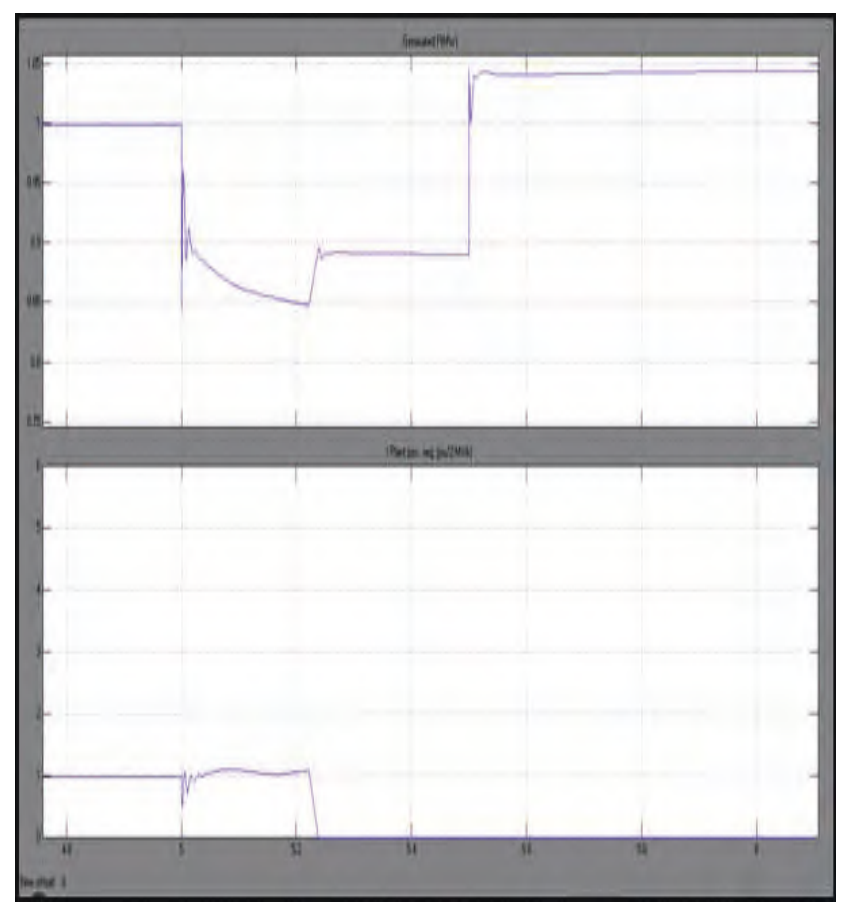

Fig.9. Wind farm power and plant current for a voltage sag.

\section{B. Simulation of fault on $25 \mathrm{kV}$ system}

An L-G fault is programmed to occur at $25 \mathrm{kV}$ line at B25 bus. Fault is programmed to occur at $\mathrm{t}=5 \mathrm{Sec}$.During the voltage regulation mode of turbine, the positive sequence voltage at the terminals of wind turbine drops to nearly $80 \%$ during the fault, which is above threshold value $(75 \%)$ and now wind farm stays in operation even under fault conditions. Voltage and power of the wind farm are shown in Fig.10. 


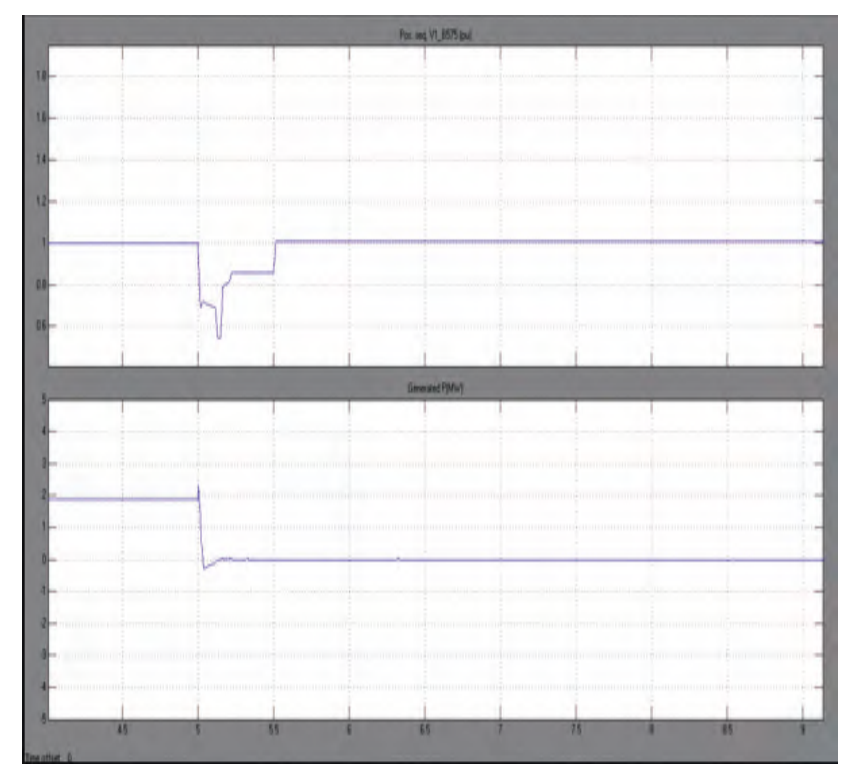

Fig.10.wind farm voltage and power for L-G fault in voltage regulation mode

\section{Simulation of fault on $25 \mathrm{kV}$ system with VAR regulation}

Different types of faults both symmetrical and asymmetrical faults are simulated on $25 \mathrm{kV}$ bus with wind turbine control parameters in VAR regulation mode. It is found that when the voltage of the wind farm drops to $70 \%$ of base value, the under voltage protection trips the wind farm. TABLE I shows the tripping times of the wind farm for different types of faults.

TABLE I.

TRIP TIME OF WINDTURBINE FOR DIFFERENT FAULTS

\begin{tabular}{|l|l|}
\hline Type of Fault & Trip time in $\mathrm{ms}$ \\
\hline L-G & 115 \\
\hline LL & 110 \\
\hline LL-G & 108 \\
\hline LLL & 10 \\
\hline LLL-G & 10 \\
\hline
\end{tabular}

$D$. Simulation of $L-G$ fault on $25 \mathrm{kV}$ system for various values of ground resistance

The system is simulated for different values of ground resistance under L-G fault on $25 \mathrm{kV}$ grid and trip times of the wind turbine coupled to DFIG connected to grid are calculated. It is observed that as the ground resistance is increases the fault time is decreased. TABLE II shows the tripping times for various values of ground resistance for single line to ground fault on the grid.
TABLE II.

TRIP TIME OF WINDTURBINE FOR DIFFERENT VALUES OF GROUND RESISTANCE

\begin{tabular}{|l|l|}
\hline Ground resistance in $\mathrm{m} \Omega$ & Trip type in $\mathrm{ms}$ \\
\hline 0.01 & 10 \\
\hline 1 & 9 \\
\hline 1000 & 5 \\
\hline
\end{tabular}

E. Simulation of $L-G$ fault on $25 \mathrm{kV}$ system for various values of Transmission line lengths

A 9MW Doubly fed induction generator connected to $25 \mathrm{kV}$ grid is simulated for L-G fault on grid for different values of transmission line lengths and is found that trip time increases as the transmission line length increases indicating that DFIG trips at faster rate for the faults nearer to the DFIG. TABLE III shows tripping times of wind turbine for different values of transmission line lengths for L-G fault on grid.

TABLE III.

TRIP TIME OF WINDTURBINE FOR DIFFERENT VALUES OF TRANSMISSION LINE LENGTHS

\begin{tabular}{|l|l|}
\hline \multicolumn{1}{|c|}{ Transmission line length in $\mathrm{kM}$} & \multicolumn{2}{c|}{ Trip type in ms } \\
\hline 6 & 112 \\
\hline 8 & 113 \\
\hline 10 & 115 \\
\hline
\end{tabular}

\section{CONClusions}

In this paper, basic operation of the DFIG and power flow in the DFIG are discussed. The performance of DFIG along with Superconducting magnetic energy storage system is studied. Effect of voltage sags and low voltage ride through capability of DFIG and different configurations of crow bar circuits are also discussed. A Matlab simulink model of DFIG connected to the grid is simulated for different types of faults and the trip times of the wind turbine are recorded and found that as the intensity of the fault increases the trip time of the wind farm decreases.

\section{REFERENCES}

[1] G V.Akhmatov, „Modelling of Variable Speed Wind Turbines with Doubly -Fed Induction Generators in Short Term Stability Analysise, Proceedings of the 3rd International Workshop on Transient Networks for Offshore Windfarms ,Stockholm,April 11-12,2012

[2] Flores mendes V,De Souja C.V,Rocha Silva.S Cezal Rabalo "modeling and ride through control of Doubly Fed induction generator during symmetricak sags",IEEE transactions on energy conversion, dec 2011

[3] Slootweg J.G.,H.Polinder,W.L.Kling;" Dynamic modeling of a wind turbine with doubly fed induction

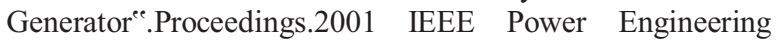
Society Summer Meating,IEEE Power Engineering Society,S.1.,2001,p.1-6. 
[4] M. Wegmuller, J. P. von der Weid, P. Oberson, and N. Gisin, "High Resolution fiber distributed measurements with coherent OFDR," in Proc. ECOC'00, 2000, paper 11.3.4, p. 109.

[5] M.RI.Sheikh,S.M.Muyeen,R.Takahashi,T.Murataand J.Tamura,"Transient stability enhancement of wind -turbine generator using super conducting magnetic energy storage unit " in $18^{\text {th }}$ Int.Conf.Elect.Machines ,2008,pp.1-6

[6] T.kinjo T.senju,N.Urasaki nad H.fujit "terminal voltage and output power regulation of wind -turbine generator by series and parallel compensation using SMES"in IEE proc.gen.transmiss.distrib.2006,vol.153,no 3,pp.276-282.

[7] C.J.Liu,C.SHu,X.Li,Y.Chen,M.Chen and D.HXu "Applying SMES to smooth short term power fluctuation in wind farms "in IEE $34^{\text {th }}$ annual conf.Ind.Electron,.2008,pp.3352-3357.

[8] M.H.Ali,J.Tang and B.Wu,"SMES strategy to minimize frequency fluctuations of wind generator system" in IEE $34^{\text {th }}$ Annual Conf. .Ind.Electron,.2008,pp.3382-3387.

[9] G.Manohar, Rajib Kumar Kar," Analysis of doubly Fed Induction Generator connected to grid" IEEE international conference ICARET-13

[10] M.H.J. Bollen , G. Olguin, M. Martins, "Voltage Dips at the Terminals of Wind Power Installations" Nordic Wind Power Conference, march 1-2, 2004.

[11] J. Niiranen, "Voltage ride through of a doubly-fed generator equiped with an active crowbar", Nordic Wind Power Conference, march 1-2, 2004.

[12] K.E. Okedu, S.M. Muyeen, R. Takahashi and J. Tamura, "Wind Farms fault ride through using DFIG with new protection scheme," IEEE Trans. Sustainable Energy, vol. 3, n³, pp. 242-254, April 2012.
[13] S.M. Muyeen, R. Takahashi, T. Murata, J. Tamura, M.H.Ali Y.Matsumura, A. Kuwayama and T. Matsumoto, "Low voltage ride through capability enhancement of wind turbine generator system during network disturbance," IET Renewable Power Generation, vol. 3, n 1, pp. 65-74, 2009.

[14] F. Díaz-González, A. Sumper, O. Gomis-Bellmunt and R. Villafáfila- Robles, "A review of energy storage technologies for wind power applications," Renewable and Sustainable Energy Reviews, vol. 16, n ${ }^{\circ}$, pp. 21542171, May 2012.

[15] A.H.M.A. Rahim and E.P. Nowicki, "Supercapacitor energy storage system for fault ride-through of a DFIG wind generation system," Energy Conversion and Management, vol. 59, pp. 96-102, July 2012.

[16] A.H.M.A. Rahim and E.P. Nowicki, "Supercapacitor energy storage system for fault ride-through of a DFIG wind generation system," Energy Conversion and Management, vol. 59, pp. 96-102, July 2012.

[17] M.J. Hossain, H.R. Pota, V.A. Ugrinovskii and R.A. Ramos, "Improved low-voltage-ride-through capability of fixed speed wind turbines using decentralised control of STATCOM with energy storage system," IET Generation, Transmission \& Distribution, vol. 6, n8, pp. 719-730, 2012.

[18] C. Abbey and G. Joos, "Supercapacitor energy storage for wind energy applications," IEEE Trans. IndustryApplications, vol. 43, n³, pp. 769- 776, May-June 2007.

[19] P.S. Flannery and G. Venkataramanan, "A fault tolerant doubly fed induction generator wind turbine using a parallel grid side rectifier and series grid side converter," IEEE Trans. Power Electronics, vol. 23, n³, pp. 1126-1135, May 2008. 